\title{
Role of Community Leaders in Efforts to Preserve Literacy Tradition
}

\author{
Alim Harun Pamungkas \\ Universitas Negeri Padang, Padang, Indonesia \\ e-mail: pamungkasd527@.gmail.com
}

\begin{abstract}
Literacy is one of human life needs that cannot be avoided. Literacy needs to be created by society as a new norm in the society. The aim of a literacy program is to change individuals and their social behaviors which do not care to become members of a society who care not only about their individual skills in literacy such as reading, writing and counting, but also about change which their society needs. Literacy learning is done formally by the government through schools, non formal education centers, such as PKBMs, TBMs, and other formal institutions, and undertaken informally by communities through family education. Literacy learning program is supposed to be conducted by society continuously and sustainably to keep their literacy skills. Familiarizing literacy in daily activities is an important part of the development of literacy culture. The growth of literacy culture can be accelerated through the active involvement of formal or informal community leaders in a society. Leadership of community leaders is the main determinant of successful literacy learning in the community. Community leaders easily use their influence to change people's behavior from illiterate to literate. It is an important thing for the informal leaders to understand about their core competence as leaders in communication skills with society for positively influencing their people's mind, will, and act for using the literacy knowledge and skills in daily activities.
\end{abstract}

Keywords: informal community leader, literacy

\section{INTRODUCTION}

The definition of literacy can be explained by categorizing it into literacy and functional literacy [1]. The Indonesian term for literacy is "keaksaraan". It is a noun derived from word "aksara". Etymologically, literacy is a graphic sign system used by humans to communicate and represent their speech. It is also known as "keberaksaraan" that means the ability to read and write.

According to the terminology, literacy is defined as an effort to switch the use of mother tongue as the only language to communicate into comprehension of the national language. Furthermore, literacy is not only associated with reading skill but also writing and counting. The common term used is "calistung" (baca, tulis, hitung). In brief, literacy is the effort to identify, reproduce, and use the graphic sign system as the rules.

Besides, functional literacy consists of the words "literacy" and "functional". Functional is from the word "function". Based on the terminology, function is a set of activities done to get results as expected. Therefore, the functional literacy is the efforts to identify, reproduce, and use the literacy as needed in daily life. In other words, functional literacy means using "calistung" in daily life.

Merrifield had explained that over time, views of what literacy means have shifted from academic skills such as decoding text, to functional skills, such as being able to perform certain tasks using literacy skills. Recent research has changed radically our understanding of literacy. Literacy is now described as multiple "literacies" rooted in particular social contexts. This change in definition shifts the focus even further from abstract skills to real-life practices [3].

The knowledge and skills of reading, writing, and counting should be internalized by each literate individual. It will help them to perform their daily activities in the family, office, and social interaction. The ability to internalize the literacy in the daily life only occurs when the individuals and their social environment already have a literacy awareness. The literacy effort should be done formally by the government and informally by the society. It is undertaken through some institutions such as schools, learning centers, reading centers, and informal institutions like families. 


\section{RESULTS AND DISCUSSION}

\subsection{Literacy Education}

The literacy education is aimed to change individuals and society's behavior to have an awareness to literacy. It is not only associated with reading, writing, and counting skills, but also applying those knowledge and skills in interaction among individuals in society.

Merrifield (1998) raises an intriguing question "Does literacy have value in itself, or only because of its social impacts?". Can literacy education empower the society?, or Can literacy education liberate the society from their marginalization and underdevelopment?. The answers depend on the characteristics of the literacy education organized. Furthermore, it depends on ways to define what and what for the literacy education is [3].

The literacy education defined as a subject matter based on the school view of literacy (only about the mastery of reading and writing techniques or only reducing the number of illiterate people) will not give any social impacts. It is contradicted with the fact that the public investment in the literacy education is due to its social impacts. As stated by Merrifield that the social impacts of literacy appear to be the guiding purpose for public investment in literacy education [3].

\subsection{Idealism and Facts}

Adult literacy education is known as adult basic education. It is commonly assumed as an instrument in the social and economic recovery. The literacy education essence is the impact of social and economic recovery [4].

The literacy education considers giving the basic abilities (technical and functional) that can be applied to improve the quality of daily life [5].

The literacy is not meaningful within itself. As stated by Merrifield [3] that adult basic education has long been viewed by many educators and policy makers as a tool for addressing social and economic problems [6]. In line with that, Faisal asserts that literacy education or literacy program is widely conceptualized as an effort to serve adults to acquire basic educational skills necessary to literate functioning. The ultimate goal is to improve the quality of life of participants [7].

The literacy is considered functional in supporting the main roles of adults as workers and members of family and society. Therefore, the life quality of those who have literacy is improved socially and economically [6].
The assumption of the instrumental as the literacy education character is called an autonomous view of literacy. It is caused by strong assumption that the literacy is a set of technical skills which will be transferable from a context to another if it is already mastered and automatically followed by the social and economic recovery.

The literacy is considered as the best solutions over the various forms of underdevelopment and marginalization. The national or international public policies still keep up on the autonomous view of literacy [3]. The functional literacy is a part of the autonomous view of literacy as stated by Marrifield, functional and competency approaches to literacy assume that knowing how well someone reads tell us something about how they carry on the rest of their lives. In contrast, Merrifield states that there is not a great deal of evidence for this.

Merrifield's last statement above shows a gap between literacy functioning and what happens in the real life. In other words, when people are not illiterate, they are not automatically successful in improving their quality of life. That gap should be addressed by doing actions to fix it. There should be a courage to give a total correction to the autonomous view of literacy, including the functional approach and competence in defining literacy [3].

\subsection{Literate Society}

The socio-cultural theories of literacy are important signals to change the perspective of the society about the literacy more radical. The literacy education is not only considered as the achievement of technical and functional mastery, but also as the socio-contextual practice. Thus, the literacy is no longer interpreted as the subject matter but as a practice based on the social context.

The example of the literacy practice in the social context on campus is lecturers or college students read and write scientific papers. It is the social practice required for the academics. It is different from the social context in the society such as farmers. The literacy practices needed in agriculture are taking notes of the planting, fertilizing, spraying period, harvest, and so forth; recording the fund, production cost, income, and debt and receivable; reading the instructions of using fertilizer, fertilization rules, and other forms of literacy needed in the daily practices of farming society [7].

Every social context has their literacy demand. The different social contexts need the different literacy practices. Thus, someone should master the various literacy practices based on their social contexts. Gee states that literacy is not something we 
do with our heads but something to do with social, institutional, and cultural relationships [7].

The thought above insists the importance of presenting the real life events to be read in the literacy education. It does not only present the literacy materials as needed in the real life, but also contain the understanding, critical question of the various sides and details. Besides related to the cognitive aspect, the literacy education is also used in sharpening the brain to read the world behind the words read.

Bringing out the daily life to read is an essential characteristic of the literacy education. Through the learning process of reading the words and real life, it is expected to create the literacy education which is culturally relevant and empower socially [8]. [7] summarizes that the kind of literacy education explained is voiced by some experts such as [9], [10], [11], [12], and [13].

The type of literacy education, in which the content and material are relevant with the society demand in the real life, is needed to obtain the two essential characteristics mentioned. It should also be dialogic, reflecting the high involvement of the learners in order to be able to express their curiosity and opinion about the real life they faced. When the dimensions of life, which are contextualized and dialogic, have been actualized, they will educate, empower, and preserve the literacy practices as the social practices in the daily life.

\subsection{Role of the Government and Public Figure}

Literacy is an innovation. The innovative diffusion perspective [14]. Rogers explains five stages to adopt an innovation or a new thing: knowing, being interested, trying, applying, and being accustomed. The literate people only need to accustom or internalize the literacy in their daily activities. Meanwhile, the illiterate people need to know the literacy, have the interest, practice, and accustom it.

Based on the Rogers's opinion, the literacy is a form of innovation that should be a habit in the daily life [14]. The individuals need to put it as a necessity of life that cannot be avoided. The society also needs to make it as a norm in the social life. For example the farming society may practice the literacy through reading the instruction of using pesticide and recording their period activities, the type and amount of expenditure production and income earned, and the identities of their business partners [15]. In the social life, the village chief as a public figure could accustom the literacy through distributing the result of meeting (the minutes) to all residents. This is a practical attempt to socialize the literacy in the individual's life and society.

The explanations above clearly indicate that literacy habituation is an important part of the literacy growth. The literacy growth can be accelerated through the active public figures both formal and informal in the society. The public figures' leadership becomes the main determinant to the success of literacy learning programs in the society. It is caused by the structural position of the formal public figure such as the village chief and the personal closeness influence of the informal public figure such as ulama, kepala adat, and penghulu within the society. The public figures' influences will change the illiterate society to be literate society easily.

The public figures absolutely have the social interaction skills because structurally they have a function to ensure the entire socialization process (social interaction to change the asocial condition to be socialized to prevent the anti-social society) [16]. Based on that function, in the functional literacy context, the public figures have the important roles to realize a social condition in which the society use the literacy knowledge and skills they have.

\section{CONCLUSIONS}

The literacy education program should be continued and sustainable to maintain the knowledge and skills of reading, writing, and counting. The low intensity of reading, writing, and counting usage in the daily life leads to the decrease of the knowledge and skills possessed. The literacy learning programs might be a new thing for individuals who have not master reading, writing, and counting in the simplest forms yet. However, it might be a usual thing for individuals who enjoyed the benefits of the knowledge and skills of literacy usage in their daily life.

The literacy education suited with the social context demand of the people in the city will enable them to practice the literacy in their daily life. Moreover, there might develop various understanding and critical awareness among the society against their real life such the type and flow of public services provided by the government, the taxes paid, the participation in the legislation, the retribution, and etc. The results of the understanding and critical awareness is the start point of various practical efforts to solve the problems which limit the participation of the society in the regional development.

The public figures should realize that their leadership core competence is the ability to communicate with the society to influence their 
thoughts, desires and actions. Therefore, it will actualize the learning atmosphere built with the awareness, desire and new action of the society to involve the literacy knowledge and skills in their daily life.

\section{REFERENCES}

[1] A. M. Abudu, M. N. Fuseini, and Y. Nuhu, "Complementary Role of Functional Literacy Programs in Accelerating Literacy Rate in Ghana," vol. 1, no. 11, pp. 1-16, 2013.

[2] V. D. O. Andreotti, "Critical Literacy: Theories and Practices," Policy Prat. A Dev. Educ. Rev., vol. 1, no. 1, pp. 12-32, 2007.

[3] J. Merrifield, "Contested Ground: Performance Accountability in Adult Basic Education," Tennessee, 1998.

[4] J. C. Ihejirika, "Utilization of Adult and NonFormal Education Programs in Combating Rural Poverty in Nigeria," World J. Educ., vol. 2, no. 3, pp. 25-31, 2012.

[5] M. M. G. Sywelem, "Literacy and Adult Education in Egypt: Achievements and Challenges," Am. J. Educ. Res., vol. 3, no. 7, pp. 793-799, 2015.

[6] A. D. Arko and K. Addison, "The Impact of Functional Literacy on Socio-Economic Lives of Beneficiaries: A Case Study of The Agona District of Ghana," Edo J. Couns., vol. 2, no. 2, pp. 199-213, 2009.

[7] S. Faisal, "Pendidikan Keaksaraan Keluarga: Tawaran bagi Pengembangan Pembelajaran Program Keaksaraan di Indonesia," 2004. [Online]. Available: http://journal.um.ac.id/index.php/jtep/article/vi ew/2776.

[8] S. C. Degener, "Making Sense of Critical Pedagogy in Adult Literacy Education," 2005. [Online]. Available: http://www.ncsall.net/index.html@id=562.htm 1.

[9] E. R. Auerbach, "Toward a Social-Contextual Approach to Family Literacy," 1989. [Online]. Available:

http://hepgjournals.org/doi/10.17763/haer.59.2. h237313641283156.

[10] P. Freire, Pedagogy of The Oppressed, vol. 35, no. 1. New York: The Continuum International Publishing Group Inc. The Continuum International Publishing Group Ltd, 1993.

[11] I. Shor, Empowering Education Critical Teaching for Social Change. Chicago: The
University of Chicago Press, 1992.

[12] C. Lankshear and P. L. McLaren, Critical Literacy: Politics, Praxis, and the Postmodern. New York: State University of New York Press, 1993.

[13] B. A. Quigley, Rethinking Literacy Education. The Critical Need for Practice-Based Change. The Jossey-Bass Higher and Adult Education Series. San Fransisco: Jossey-Bass Publishers, Inc., 1997.

[14] E. M. Rogers, Diffusion of innovations, 3rd ed. New York: The Free Press A Division of Macmillan Publishing Co., Inc, 1983.

[15] S. Y. Gombe, T. Bin Suandi, I. A. Ismail, and Z. Omar, "Extension Education's Role towards Community Empowerment in Nigeria: Issues, Challenges and Prospects," vol. 3, no. 2, pp. 135-142, 2016.

[16] I. . Abbass, "Community Participation in Education: Challenges and Prospects in Nigeria's Democracy," Eur. Sci. J., vol. 8, no. 5, pp. 1-11, 2015. 